\title{
Response to selection for seed yield in six white clover cultivars
}

\author{
K.H. WIDDUP ${ }^{1}$, D.R. WOODFIELD ${ }^{2}$, I.J. BAIRD ${ }^{1}$ and P.T.P. CLIFFORD ${ }^{1,3}$ \\ ${ }^{1}$ AgResearch, Canterbury Agriculture and Science Centre, P.O. Box 60, Lincoln \\ ${ }^{2}$ AgResearch, Grasslands Research Centre, PB 11008, Palmerston North \\ ${ }^{3}$ Retired, 26 Browns Road, Christchurch \\ keith.widdup@agresearch.co.nz
}

\begin{abstract}
The successful commercialisation of agronomically superior white clover (Trifolium repens) cultivars is dependent on their seed production potential. Field trials were established in 2000 and repeated in 2003 to determine the impact of selection for increased seed yield. The seed yield of the pre-release cultivar (the base population prior to selection for seed yield and cultivar release, representing generation 0 ) was compared with the field Nucleus generation of the released cultivar (second generation after selection for seed yield, representing generation 2) and the Basic seed generation (the fourth generation after selection for seed yield, representing generation 4), in six recent cultivars (Grasslands Kopu II, Grasslands Challenge, NuSiral, Grasslands Sustain, Grasslands Demand and Grasslands Prestige). The Nucleus and Basic generations had consistently higher seed yield than the pre-release generation for all cultivars. These increases in seed yield were associated with increases in inflorescence density (inflorescences $/ \mathrm{m}^{2}$ ) and to a lesser extent with increased seed yield/inflorescence. Changes were also evident in flowering pattern with four of the six cultivars having a sharper flowering peak following selection. This improved uniformity was also evident through reduced variability in leaf size of the Nucleus generation compared to the pre-release generation. Grasslands Kopu II had the highest seed yields which were associated with moderately high inflorescence density in combination with high seed yield/ inflorescence. The selection strategy used in the final phase of the development of these cultivars has proven successful in increasing seed yield through refining flowering pattern and production while maintaining the morphology and uniformity of the new cultivar.
\end{abstract}

Keywords: cultivars, genetic improvement, seed production, Trifolium repens, white clover

\section{Introduction}

The successful commercialisation of agronomically superior white clover (Trifolium repens) cultivars is as dependent on their seed production potential as on their agronomic attributes. Absence of a reliable supply of competitively priced seed has resulted in the commercial failure of many white clover cultivars that otherwise had good agronomic performance, including cultivars such as Tillman from the USA and Siral from Australia (Davies 1984; Woodfield \& Caradus 1994). White clover breeders operating outside of the major international seed production regions have had less opportunity to select for reproductive characters when finalising the parent lines of a new cultivar (Falcinelli 1999). In New Zealand, the increasing pressure on cropping area (Pyke et al. 2004) has further intensified the need for high seed yield potential.

Currently in New Zealand, AgResearch develops new white clover cultivars in partnership with seed companies as outlined by Hay et al. (1996). In the final stages of the breeding programme, a selection strategy has been implemented to ensure that new cultivars have a commercially acceptable seed yield and morphological uniformity (Clifford et al. 1996). This strategy involves screening elite agronomic populations for parents with suitable seed yield and consistent flowering pattern prior to release and commercial multiplication of a new cultivar. Individual genotypes from each pre-release cultivar are grown in Canterbury, New Zealand's main seed production region, as spaced plants in the field, and the final parental genotypes are selected based on their flowering pattern, seed yield, resistance to leaf diseases and desired plant morphology. These elite genotypes are cloned for pre-nucleus seed multiplication under stringent isolation. Finally, the seed production potential and morphology of the new cultivar are reassessed during the field Nucleus (approx. $0.3 \mathrm{ha}$ ) increase with a minimum isolation distance of $400 \mathrm{~m}$.

This paper reports on trials established to assess the impact of this selection strategy on the seed yield potential of six white clover cultivars through several generations of commercial seed multiplication.

\section{Material and methods Site}

The field trials were established in 2000 and repeated in 2003 at the AgResearch Lincoln Research farm in Canterbury (Lat. $43^{\circ} 38^{\prime} \mathrm{S}$ ) on a Wakanui silt loam. Canterbury is the principal region in New Zealand for white clover seed production. Lincoln has an average annual rainfall of $640 \mathrm{~mm}$ and mean summer maximum air temperature of $22^{\circ} \mathrm{C}$. Rainfall was not critical as plots were irrigated 3-4 times during the summer period. A 
key difference between the 2000-2001 and 2003-2004 years were the high temperatures in the first week of January 2004 when maximum temperatures rose above $30^{\circ} \mathrm{C}$ on 6 consecutive days.

\section{Trial design and management}

The trial design was a randomised split block with five replications planted in September 2000 and then replanted again using a different randomisation in September 2003. The main plots consisted of six white clover cultivars split by three cultivar generations as subplots. The six cultivars, in descending order of leaf size, were: Grasslands Kopu II, Grasslands Challenge, NuSiral, Grasslands Sustain, Grasslands Demand and Grasslands Prestige, all of which were released between 1991 and 2001. Information on the origins and breeding history of these cultivars is contained in Woodfield \& Caradus (1997), Woodfield et al. (2001) and Ayres et al. (2002). The three generations were the pre-release generation, which represents the base population developed through agronomic selection but before selection for seed yield (generation 0), the Nucleus generation produced in the field after selection for seed yield (generation 2) and the Basic seed generation produced by commercial growers (generation 4). In both years, plants of each generation and cultivar were established in the greenhouse in June, hardened outside in August and planted into the field in September. Prior to planting, trifluralin (Treflan at $21 /$ ha) was incorporated into the soil to control potential weeds. Each sub-plot consisted of 4 rows of 7 plants inserted $30 \mathrm{~cm}$ apart, which formed a canopy by early December. Any volunteer white clover plants were hand weeded before stolons covered the plots. Standard soil quick tests indicated adequate levels of phosphorus, potassium and sulphur in both years but boron (Bortrac at $21 /$ ha) was applied in October. Plots were irrigated 3-4 times as required based on leaf turgor between November and February of both seasons. Plots were sprayed two weeks before seed harvest in mid-February with MPCA at $1.5 \mathrm{l} /$ ha to reduce leaf herbage, and then one week before harvest with diquat (Reglone at $21 /$ ha) to desiccate the herbage.

\section{Measurements}

The rate of inflorescence appearance (number of new inflorescences produced per week) was measured from two $60 \times 30 \mathrm{~cm}$ quadrats per plot, from early-December until late-January in each season providing a flowering curve for each cultivar and generation. In mid-February of both years, the final inflorescence density (number of inflorescences $/ \mathrm{m}^{2}$ ) was measured from two $60 \times 30 \mathrm{~cm}$ quadrats per plot. Subsequently, a $2 \mathrm{~m}$ x $0.45 \mathrm{~m}$ strip was harvested through the centre of each plot to determine seed yield $\left(\mathrm{g} / \mathrm{m}^{2}\right)$. Plant morphology was recorded through a visual score of leaf size from all plants in December 2000 and by measuring the leaf area $\left(\mathrm{mm}^{2}\right)$ of 50 leaves per plot in December 2003. All parameters were analysed by ANOVA using the Genstat 7 statistical package. A combined analysis across years was used and where interactions were non-significant, only the main effects are presented. Treatment means were separated using least significant difference at a $5 \%$ probability level $\left(\mathrm{LSD}_{0.05}\right)$.

\section{Results and discussion Generation effect}

Although the average white clover seed yields were significantly greater $(\mathrm{P}<0.05)$ in 2001 compared with 2004 (1030 cf. $830 \mathrm{~kg} / \mathrm{ha}$ respectively), the increases in seed yield between the generations were consistent in both years. The pre-release generation represents the end product of the agronomic selection programme prior to any selection for seed yield. This pre-release generation had consistently lower seed yield than the Nucleus and Basic generations for all cultivars (Figure 1A). The selection strategy used to improve the seed yield of these cultivars has been successful as shown by the $21 \%$ increase in seed yield from the pre-release to Nucleus generation and the further $10 \%$ increase to the Basic generation. This additional increase in seed yield between the Nucleus and Basic generations despite the apparent removal of selection pressure, may be explained by an increase in the frequency of highly reproductive genotypes in subsequent generations resulting in an increased allele frequency for the major seed yield traits. The ability to select for seed production in the main seed production region should provide New Zealand-bred cultivars with a commercial advantage over overseasbred cultivars that are currently being multiplied in Canterbury.

Earlier research showed that inflorescence density and seed yield per inflorescence, were two key components of white clover seed production (Clifford 1987; Clifford 1993; Van Bockstaele \& Rijckaert 1988). Increases in seed yield across the three generations were associated with increases in both inflorescence density and seed yield per inflorescence (Figure 1B). The inflorescence density improved significantly going from the pre-release stage to the Nucleus stage, which was similar to the Basic generation stage. Seed yield per inflorescence showed a similar response with a significant increase between the pre-release and Basic generations (Figure 1B). Woodfield et al. (2004) also showed that both of these mechanisms are responsive to selection and can be manipulated separately or in combination to improve seed yield.

Jahufer \& Gawler (2000) suggested that screening and selection for seed yield would be most effective if 
Figure 1 The seed yield $(\mathrm{kg} / \mathrm{ha})(\mathrm{A})$ and inflorescence density (inflorescence/ $/ \mathrm{m}^{2}$ ) ( - - ) and seed yield ( $\mathrm{g} /$ inflorescence) (…...) (B) for the pre-release, Nucleus and Basic generations averaged for the six white clover cultivars in 2001 and 2004. Bars indicate the LSD $(P<0.05)$.
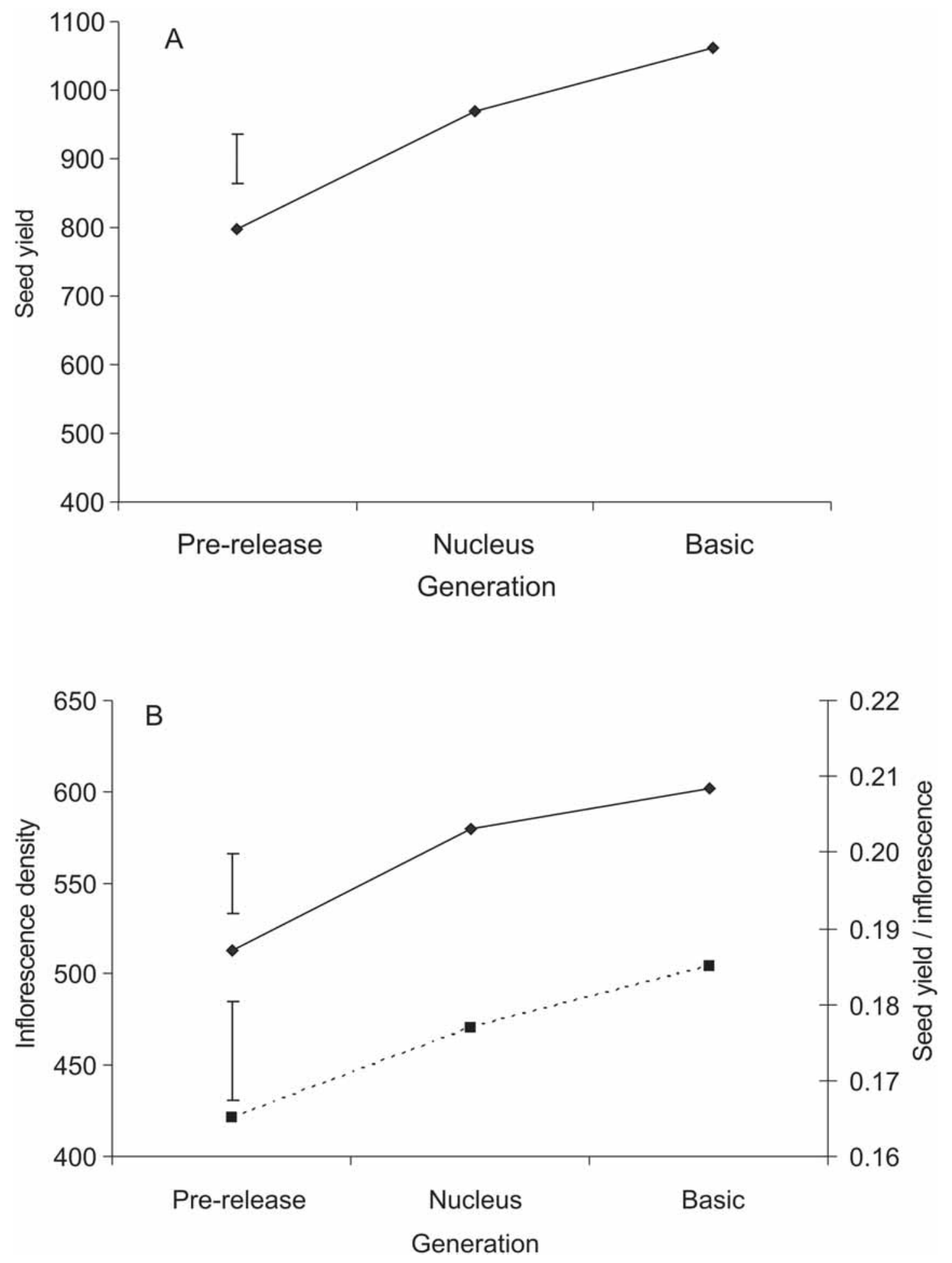
Figure 2 The seed yield of the six white clover cultivars in 2001 ( $\square$ ) and 2004 ( $\square$ ), averaged across seed generations. The bar indicates the LSD $(P<0.05)$.

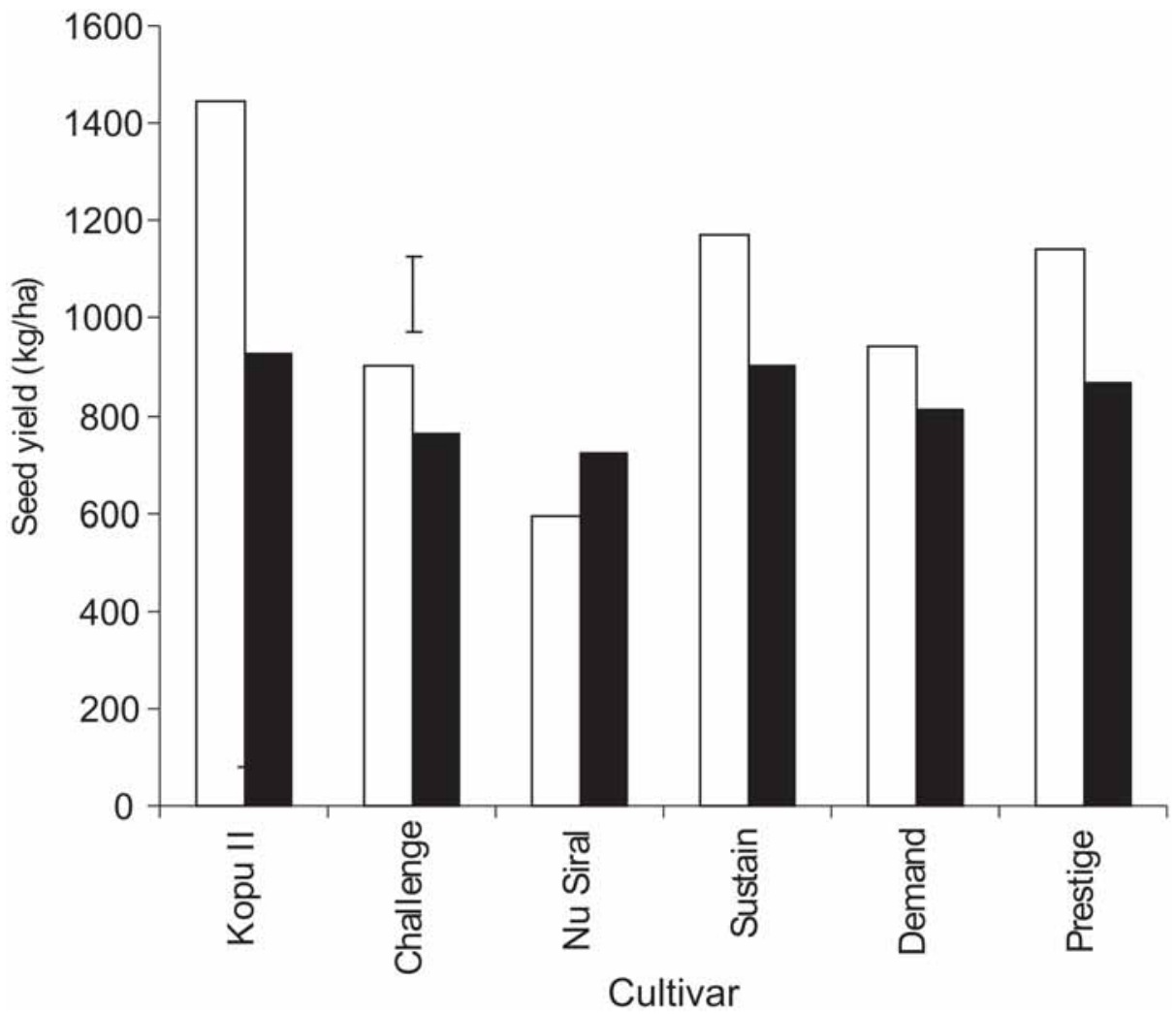

done simultaneously with selection for agronomic value of a new cultivar. However, this study has shown marked improvements in seed yield from one cycle of selection at the final stages of the breeding programme. Annicchiarico et al. (1999) and Woodfield et al. (2004) estimated high heritability values (0.4-0.9) for seed yield components such as inflorescence density, florets/ inflorescence and seed yield/ha indicating effective selection for these characters is possible at any stage in the programme. Leaving the selection to the final stages is cost effective and allows the major emphasis to be focused on the agronomic features of the new cultivar during the breeding programme. A separate study is required to determine whether the final selected cultivar maintains the agronomic features compared with the prerelease cultivar.

\section{Cultivar effect}

There was a significant cultivar $\mathrm{x}$ year interaction due mainly to NuSiral producing greater seed yields in 2004 than in 2001, whereas the other 5 cultivars had lower seed yields in 2004 (Figure 2). The higher NuSiral yields were associated with a higher inflorescence density in 2004 than in 2001 while the reverse was true for the other cultivars. NuSiral is derived from North African germplasm and is earlier flowering than the other cultivars. This resulted in a greater proportion of the total inflorescences appearing before the extreme temperatures were experienced in early-January 2004. In contrast, the other cultivars are medium-late flowering types and showed a steep decline in inflorescence density in January 2004.

There was greater separation among the cultivars for seed yield in 2001 compared with 2004 which may be attributed to the hot January period limiting seed production in 2004, thereby preventing the cultivars from expressing their full genetic potential. In 2001, Kopu II produced the highest seed yield $(\mathrm{P}<0.05)$ followed by Sustain and Prestige (Figure 2). NuSiral was the lowest yielding cultivar in both years, with Challenge and Demand also having lower seed yields (Figure 2). The high seed yield potential of Kopu II goes against the accepted trend. In general, cultivars with smaller leaves have higher stolon density, inflorescence density and potential seed yield (Clifford 1986, 1987). Kopu II is a large-leaved clover selected for dairy systems that has higher stolon density than would normally be expected for a large-leaved cultivar 
Figure 3 The rate of inflorescence production for the pre-release (-), Nucleus (.......) and Basic (- -) generations for Kopu II, NuSiral and Prestige in 2001.
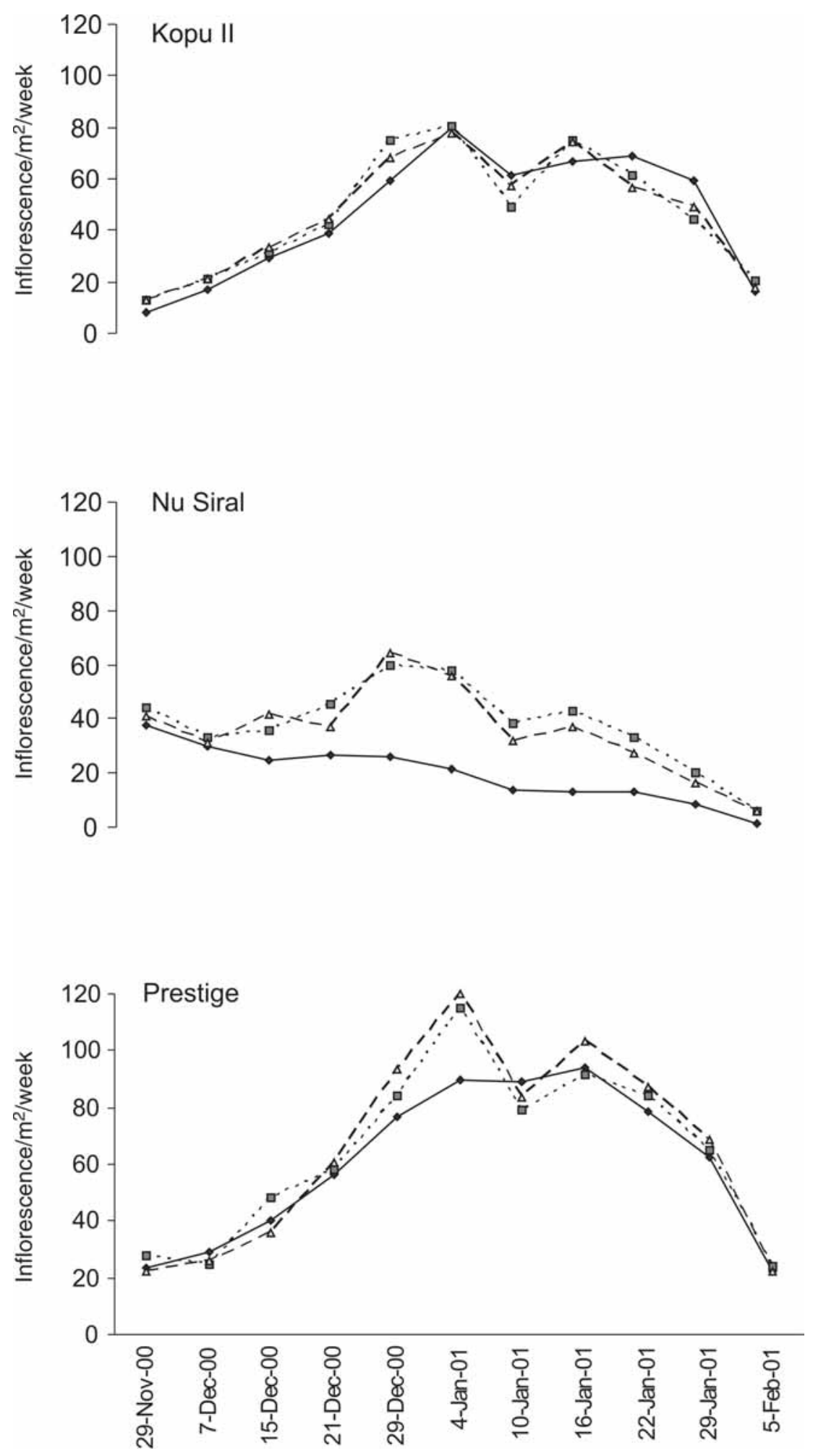
Table 1 The inflorescence density and seed yield for the three generations of the six white clover cultivars averaged for 2001 and 2004.

\begin{tabular}{|c|c|c|c|c|c|c|}
\hline \multirow[b]{2}{*}{ Cultivar } & \multicolumn{3}{|c|}{ Inflorescence density $\left(\mathrm{no} . / \mathrm{m}^{2}\right)$} & \multicolumn{3}{|c|}{ Seed yield (g/inflorescence) } \\
\hline & Pre-release & Nucleus & Basic & Pre-release & Nucleus & Basic \\
\hline Kopu II & 535 & 525 & 510 & 0.232 & 0.227 & 0.254 \\
\hline Challenge & 435 & 535 & 610 & 0.143 & 0.164 & 0.172 \\
\hline NuSiral & 260 & 375 & 450 & 0.165 & 0.198 & 0.188 \\
\hline Sustain & 515 & 580 & 630 & 0.188 & 0.178 & 0.178 \\
\hline Demand & 455 & 545 & 530 & 0.164 & 0.183 & 0.178 \\
\hline Prestige & 875 & 920 & 890 & 0.098 & 0.114 & 0.132 \\
\hline $\operatorname{LSD}_{\mathrm{c}}(5 \%)$ & & 55 & & & 0.025 & \\
\hline $\operatorname{LSD}_{\mathrm{C} \times \mathrm{G}}(5 \%)$ & & 85 & & & NS & \\
\hline
\end{tabular}

Table 2 The mean leaf area $\left(\mathrm{mm}^{2}\right)$ and standard deviation (SD) from 50 leaves per plot of the six white clovers for the pre-release, Nucleus and Basic generations in 2004.

\begin{tabular}{|c|c|c|c|}
\hline \multirow[b]{2}{*}{ Cultivar } & \multicolumn{3}{|c|}{ Leaf area $\left(\mathrm{mm}^{2}\right)-$ standard deviation } \\
\hline & Pre-release & Nucleus & Basic \\
\hline Kopu II & $705 \pm 300$ & $840 \pm 185$ & $805 \pm 150$ \\
\hline Challenge & $650 \pm 220$ & $630 \pm 155$ & $600 \pm 150$ \\
\hline NuSiral & $540 \pm 170$ & $635 \pm 150$ & $645 \pm 160$ \\
\hline Sustain & $570 \pm 170$ & $570 \pm 140$ & $570 \pm 140$ \\
\hline Demand & $455 \pm 155$ & $520 \pm 130$ & $485 \pm 130$ \\
\hline Prestige & $295 \pm 120$ & $375 \pm 95$ & $380 \pm 105$ \\
\hline Mean LSD ${ }_{\mathrm{C}}(5 \%)$ & \multicolumn{3}{|c|}{95} \\
\hline SD $\quad$ LSD $_{\mathrm{C} \times \mathrm{G}}(5 \%)$ & \multicolumn{3}{|c|}{50} \\
\hline
\end{tabular}

(Woodfield et al. 2001). The combination of moderately high inflorescence density and high seed yield per inflorescence (Table 1) has resulted in an unusually high seed yield for a large-leaved cultivar. The small-leaved Prestige also achieved high seed yields but through a strategy of very high inflorescence density and lower seed yield per inflorescence (Table 1). The lowest seed yielding cultivar, NuSiral, had consistently low inflorescence density. These small-plot results indicate that with the exception of NuSiral, these cultivars each have the potential to produce seed yields of more than $1000 \mathrm{~kg} /$ ha (Figure 2).

\section{Flowering curve}

The flowering patterns (number of inflorescences produced per week) during the 2000-2001 season of three representative cultivars, Kopu II (large-leaved), $\mathrm{NuSiral}$ (medium-leaved) and Prestige (small-leaved) over the three generations are shown in Figure 3. $\mathrm{NuSiral}$ had the most dramatic change in flowering pattern. The original cultivar, Siral, (the pre-release generation in this study) had low inflorescence production and no peak flowering, whereas the Nucleus and Basic generations of NuSiral show a more definite flowering peak in late-December. Changes were also observed for Prestige, with the Nucleus and Basic generations exhibiting a sharper peak in flowering in early-January compared with the pre-release generation (Figure 3). Challenge and Sustain (not shown) also had similar changes in flowering pattern. The flowering pattern for Kopu II remained unchanged between generations reflecting little modification by selection as Kopu II already had a moderate-high inflorescence density. The flowering pattern of the cultivars in the 2003-2004 season showed a single peak in early January followed by a steep decline in inflorescence production due to the high temperatures experienced in early January 2004.

\section{Plant morphology}

It is essential that the morphological features (e.g. leaf size, stolon density, plant habit) of the plants making up the cultivar be maintained through the final selection phase for seed yield so as to meet PVR requirements. In general, large leaf size in white clover is associated with erect growth habit and lower stolon growing point density while small-leaved white clovers have prostrate growth habit and higher stolon density (Caradus et al, 1997). For that reason, leaf size was used as an indicator of the morphology of the different cultivars in this study.

The lack of response in seed yield for Kopu II may reflect greater selection pressure to maintain the 
morphological features of this cultivar. Kopu II was the largest-leaved cultivar and showed the greatest level of variation (standard deviation) for leaf size at the prerelease stage (Table 2). However with careful parental selection, the leaf size of Kopu II was maintained between the pre-release and Nucleus generations while variation in leaf size was reduced, resulting in a more uniform cultivar (Table 2). The medium and smallleaved cultivars showed less variation in leaf area at the pre-release stage and therefore greater emphasis was able to be placed on selection for seed yield in these cultivars.

\section{Conclusions}

1. The selection strategy used in the final phase of the breeding of these cultivars resulted in a significant improvement in seed yield proceeding from the pre-release to the Nucleus generation and a further small increase to the Basic seed generation.

2. The increase in seed yield was linked with improvement in inflorescence density and seed yield per inflorescence.

3. High seed yields by different cultivars can be achieved through different strategies. Kopu II combined above average inflorescence density with high seed yield/inflorescence whereas Prestige produced very high inflorescence density with low seed yield/inflorescence.

4. Changes were also evident in flowering pattern with four of the six cultivars having a sharper flowering peak following selection. The peaked flowering curve of NuSiral was a marked improvement on the flat curve of the pre-release generation (Siral) as a greater proportion of inflorescences are ready for harvest at the one time.

5. Improvements in seed yield can be achieved while maintaining the morphological features and improving the uniformity of the cultivars which in turn satisfies PVR requirements.

\section{ACKNOWLEDGEMENTS}

We wish to thank Agricom, Agriseeds, CropMark, Pyne Gould Guiness and Wrightson for providing Basic generation seed and Mr Kaniappa Reddy for setting up the 2000-2001 trial. We also want to highlight the significant contribution made by the late Mr Greg Sparks who produced the Nucleus seed for most of these cultivars.

\section{REFERENCES}

Annicchiarico, P; Piano, E; Rhodes, I. 1999. Heritability of, and genetic correlations among, forage and seed yield traits in Ladino white clover. Plant Breeding 118 (4): $341-350$.
Ayres, J.F.; Lane, L.A.; Caradus, J.R.; Clifford, P.T.P. 2002. Grasslands NuSiral white clover (Trifolium repens L.). Australian Journal of Experimental Agriculture 42: 1023-1025.

Caradus, J.R.; Woodfield, D.R. 1997. World checklist of white clover varieties II. New Zealand Journal of Agricultural Research 40: 115-206.

Caradus, J.R.; Clifford, P.T.P.; Chapman, D.F.; Cousins, G.R.; Williams, W.M.; Miller, J.E. 1997. Breeding and description of 'Grasslands Sustain', a medium-large leaved white clover (Trifolium repens L.) cultivar. New Zealand Journal of Agricultural Research 40: 1-7.

Clifford, P.T.P. 1986. Interaction between leaf and seed production in white clover (Trifolium repens). Journal of Applied Seed Production 4: 37-43.

Clifford, P.T.P. 1987. Producing high seed yields from high forage producing white clover cultivars. Journal of Applied Seed Production 5: 1-9.

Clifford, P.T.P; Baird, I.J. 1993. Seed yield potential of white clover: characteristics, components and compromise. Proceedings of the XVII International Grassland Congress: 1678-1679.

Clifford, P.T.P.; Sparks, G.A.; Woodfield, D.R. 1996. The intensifying requirements for cultivar change. White clover: New Zealand's competitive edge. Agronomy Society of New Zealand Special Publication 11/Grassland Research and Practice Series 6: 19-24.

Davies, W.E. 1984. A decade of progress in clover breeding. Span 27(3):129-131.

Falcinelli, M. 1999. Temperate forage seed production: conventional and potential breeding strategies. Journal of New Seeds 1: 37-66.

Hay, R.J.M; Lancashire, J.A. 1996. Cultivar development and links to industry. White clover: New Zealand's competitive edge. Agronomy Society of New Zealand Special Publication 11/Grassland Research and Practice Series 6: 15-18.

Jahufer, M.Z.Z. Gawler, F.I. 2000. Genotypic variation for seed yield components in white clover (Trifolium repens L.). Australian Journal of Agricultural Research 51: 657-663.

Pyke, N.; Rolston, M.P.; Woodfield, D.R. 2004. National and export trends in herbage seed production. Proceedings of the New Zealand Grassland Association 66: 95-102.

Van Bockstaele, E.J.; Rijckaert, G. 1988. Potential and actual seed yield of white clover varieties. Plant Varieties and Seeds 1: 159-169.

Woodfield, D.R; Caradus, J.R. 1994. Genetic improvement in white clover representing six decades of plant breeding. Crop Science 34: 1205-1213.

Woodfield, D.R.; Baird, I.J.; Clifford, P.T.P. 2004. 
Genetic control of white clover seed yield potential. J.L.; Miller, J.E.; Woodward S.L.; Caradus, J.R. Proceedings of the New Zealand Grassland Association 66: 111-117.

Woodfield, D.R.; Clifford, P.T.P.; Cousins, G.R.; Ford, 2001. Grasslands Kopu II and Crusader: New generation white clovers. Proceedings of the New Zealand Grassland Association 63: 103-108. 